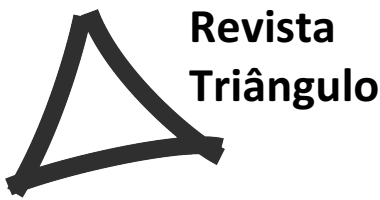

\section{FORMAÇÃO DE PROFESSORES E REPRESENTAÇÕES SOCIAIS SOBRE EDUCAÇÃO A DISTÂNCIA}

\author{
TEACHER TRAINING AND SOCIAL REPRESENTATIONS OF DISTANCE \\ EDUCATION
}

Fernanda Duarte Araújo Silva ${ }^{1}$

\begin{abstract}
RESUMO
O presente artigo expõe dados de uma pesquisa desenvolvida no curso ministrado a professores da rede pública brasileira, denominado Curso de Aperfeiçoamento em Atendimento Educacional Especializado para Pessoas Surdas, oferecido na modalidade a distância, na Universidade Federal de Uberlândia (UFU), em parceria com o Centro de Ensino, Pesquisa, Extensão e Atendimento em Educação Especial (CEPAE). O curso foi desenvolvido integralmente na modalidade de educação à distância, via Web, utilizando o Ambiente Virtual de Aprendizagem MOODLE. Temos como objetivo analisar e discutir as representações sociais dos participantes do Curso de Aperfeiçoamento Educacional Especializado para Alunos Surdos, sobre Educação a Distância (EAD). Assim, apreciamos algumas "falas" dos cursistas nos fóruns realizados em turmas do referido curso. Fundamentando-nos com as orientações e pressupostos das representações sociais na perspectiva moscoviciana. Percebemos que questões sobre autonomia, democratização e espaço geográfico, são apontadas como as principais características da EAD nas representações dos sujeitos pesquisados.
\end{abstract}

Palavras-chave: EAD. Formação de Professores. Educação.

\section{ABSTRACT}

This article presents data from a survey conducted in the course taught the teachers of the Brazilian public, called Improvement Course in Educational Service Specialist for the Deaf, offered in the distance, at the Federal University of Uberlândia (UFU), in partnership with the Education center, Research, Extension and Service in Special Education (CEPAE). The course was fully developed in education mode remotely via the Web, using the Virtual Learning Environment Moodle. We aim to analyze and discuss the social representations of the participants of the Educational Improvement Course Specialized Deaf Students on Distance Education (EAD). So we enjoy some "lines" of course participants in forums held in that course classes. Basing us with the guidelines and framework of social representations in Moscovician perspective. We realize that issues of autonomy, democratization and geographic space, are cited as the main features of the EAD in the representations of the subjects.

Keywords: EAD. Teacher training. Education.

\footnotetext{
${ }^{1}$ Universidade Federal de Uberlândia - UFU. Email: fernandaduarte.facip@gmail.com
} 


\section{INTRODUÇÃO}

O presente artigo expõe dados de uma pesquisa desenvolvida no curso ministrado a professores da rede pública brasileira, denominado Curso de Aperfeiçoamento em Atendimento Educacional Especializado para Pessoas Surdas, oferecido na modalidade a distância, na Universidade Federal de Uberlândia (UFU), em parceria com o Centro de Ensino, Pesquisa, Extensão e Atendimento em Educação Especial (CEPAE). Desde o ano de 2007, a UFU, por meio do CEPAE, faz parte da rede de formação continuada à distância de professores em Educação Especial do Ministério da Educação (MEC) e da Secretaria de Educação Especial (SEESP), em parceria com a Universidade Aberta do Brasil (UAB).

O Curso de Aperfeiçoamento em Atendimento Educacional Especializado para Alunos Surdos [Turma III], foi realizado no período de 08/2011 a 02/2012, com carga horária de 180 horas e teve por objetivo oferecer formação continuada a distância, via web, para professores da rede pública de ensino regular do Brasil que atendem ou pretendem atender a alunos surdos na modalidade de Atendimento Educacional Especializado (BRASIL, 2007).

Além disso, foi desenvolvido integralmente na modalidade de educação a distância, via Web, utilizando o Ambiente Virtual de Aprendizagem MOODLE. Os alunos contaram com o apoio de tutores e professores formadores durante todo o curso. A concepção de ensinoaprendizagem adotada neste processo de educação a distância respalda-se na interação entre os participantes do curso (aluno-professor, aluno-aluno e tutor-aluno). Esta interação foi sincrônica, desenvolvida por meio de chats, fóruns e/ou vídeo conferências e assincrônica, efetivada no ambiente virtual específico do curso (BRASIL, 2007).

Com estrutura que permite uma metodologia interativa para o ambiente web, o curso pretendeu favorecer a construção de conhecimentos teórico-práticos significativos sobre questões relacionadas ao atendimento educacional especializado para estudantes surdos, bem como fornecer informações acerca das especificidades relacionadas ao desenvolvimento psicoeducacional destes estudantes com surdez. Esse aprendizado ocorreu de forma interativa no ambiente virtual por meio da participação efetiva dos alunos em fóruns de discussões teóricas e práticas acerca da Educação Especial, das políticas públicas de inclusão escolar e da mediação pedagógica na construção do conhecimento (BRASIL, 2007). Consideramos que os fóruns de discussão na EAD possibilitam o diálogo e o debate, sendo concebidos como um dos instrumentos mais pertinentes à reflexão dos usuários do ambiente virtual.

Considerando esses pressupostos, o presente trabalho tem como objetivo analisar e discutir as representações sociais dos participantes do Curso de Aperfeiçoamento Educacional Especializado para Alunos Surdos, sobre Educação a Distância (EAD). Assim, apreciamos algumas "falas" dos cursistas nos fóruns realizados em duas turmas do referido curso, efetivado na Unidade I, intitulado: Introdução à Educação à Distância. Vale mencionar que mantivemos o anonimato de todos os sujeitos envolvidos na pesquisa.

Fundamentando-nos nessa linha, de acordo com as orientações e pressupostos das representações sociais na perspectiva moscoviciana, percebemos que os pesquisadores que estudam as Representações Sociais na perspectiva moscoviciana apoiam-se, na maioria das vezes, em um conceito construído por Jodelet (2001) que, visando esclarecer o conceito e 
os processos que formam as Representações Sociais, estudou o desenvolvimento dos conhecimentos, enfatizando sua importância no campo das ciências humanas e sociais. Ela entende as Representações Sociais como "uma forma de conhecimento socialmente elaborada e partilhada, tendo uma visão prática e concorrendo para a construção de uma realidade comum a um conjunto social" (JODELET, 2001, p.36).

Para Jodelet (2001), as representações são importantes na vida cotidiana, uma vez que nos orientam no modo de nomear e definir conjuntamente os distintos aspectos da realidade diária, no modo de interpretar esses aspectos, tomar decisões e nos posicionarmos frente a eles de forma defensiva. Desse modo, precisamos buscar informações sobre nosso mundo, nos adequarmos a ele, nos comportarmos, dominarmos física e intelectualmente, para identificar e resolver os problemas que se apresentam; por esses motivos é que criamos as representações.

Encontramos, na obra de Moscovici (2003), a definição de Representação Social como sendo:

Um sistema de valores, ideias e práticas, com uma dupla função: primeiro, estabelecer uma ordem que possibilitará às pessoas orientar-se em seu mundo material e social e controlá-lo; e, em segundo lugar, possibilitar que a comunicação seja possível entre os membros de uma comunidade, fornecendo-lhes um código para nomear e classificar, sem ambiguidade, os vários aspectos de seu mundo e da sua história individual e social (MOSCOVICI, 2003, p.21).

Vivemos em uma sociedade permeada por ideias, palavras, costumes, imagens, que se vão inserindo em nós, sem que ao menos tenhamos consciência desse processo. Assim, apesar das diferenças entre as tomadas de decisões dos grupos, somos induzidos a entender e analisar essa sociedade de maneira semelhante.

\section{Educação a Distância: vozes e percepções dos professores da rede pública do Curso de Atendimento Educacional Especializado para Alunos Surdos}

A atualidade está marcada por um modelo de desenvolvimento capitalista, voltado para os interesses de mercado e consumo de bens. Entre as mudanças geradas por esse sistema neoliberal encontramos a grande utilização das novas tecnologias, nos seus mais diversos espaços sociais, entre eles, na educação. As consequências dessa inserção das tecnologias no campo educacional podem ser superficiais ou podem ocasionar mudanças significativas na organização do trabalho pedagógico. Nessa perspectiva temos, com este trabalho, o intuito de interpretar alguns discursos que permeiam entre os professores do Curso de Aperfeiçoamento Educacional Especializado para Alunos Surdos, sobre EAD, levando em conta toda a sua singularidade.

Ao decidirmos trabalhar com a perspectiva moscoviciana sobre Representações Sociais, acreditamos que ela constitui-se como o melhor caminho para compreendermos o que pensam e quais são os conhecimentos dos professores sobre EAD. 
De acordo com Jodelet (2001), as Representações Sociais giram em torno de três questionamentos que servem de base para futuras reflexões, que são: quem sabe e de onde sabe? O que e como sabe? Sobre o que sabe e com que efeitos?

As representações dos professores sobre EAD são política e historicamente construídas e definidas por meio das experiências pessoais e coletivas. Nessa perspectiva, os professores do Curso de Aperfeiçoamento Educacional Especializado para Alunos Surdos criam e difundem os conhecimentos relativos à EAD. Vale destacar que a representação que prevalece entre os profissionais da educação, referente a essa questão, é resultado também das intervenções de diversas formas de comunicação, dentre elas a mídia.

\section{Sujeitos da Pesquisa}

De acordo com a teoria elaborada por Moscovici (2003), para apreendermos as Representações Sociais, precisamos buscá-las no diálogo. Por isso, optamos por trabalhar com um fórum de discussão desenvolvido durante o curso, pois no mesmo os cursistas expressam livremente suas representações sobre a EAD.

Analisamos uma amostra dos fóruns de discussão de duas turmas do Curso de Aperfeiçoamento Educacional Especializado para Alunos Surdos. Nessas, encontramos um total de 50 sujeitos. Desses, apenas 32 desenvolveram as atividades propostas, sendo 29 mulheres e 03 homens. Todos são professores em efetivo exercício em escolas públicas dos Estados: MG, SP, RS, DF, RO, BA, ES, SE e GO; possuem curso superior (graduação/licenciatura) e conhecimentos básicos em informática, condições necessárias à inscrição no curso, além de estarem atuando preferencialmente no Atendimento Educacional Especializado e/ou Sala de Recursos Multifuncionais de instituições escolares públicas.

De modo geral, esperamos conseguir, por meio dos fóruns, uma visão a propósito do que pensam esses sujeitos sobre EAD. Foi sugerido nessa atividade que o cursista elaborasse um conceito próprio de Educação a Distância, comentando as principais características da EAD, e refletisse sobre a seguinte questão: Você acredita que podemos estudar e aprender a distância? Por quê? A seguir, apresentaremos algumas das análises realizadas no trabalho.

\section{O que os sujeitos sabem sobre EAD e com que efeitos...}

A formação de professor constitui-se um dos eixos mais discutidos nas últimas décadas na área educacional. Segundo Silva (2005) a educação no Brasil tem sido bastante enfatizada em diversas esferas do contexto social.

Talvez o Brasil nunca tenha vivido período no qual a educação foi tão destacada nos discursos políticos e empresários, nunca se teve assegurada em lei a possibilidade de construção de projetos políticospedagógicos e gestão democrática das escolas, nunca se teve tão 
facilitado o acesso à informação e à bibliografia internacional, nunca se dispôs de tamanha diversidade de materiais e veículos para instrumentalizar o processo o processo educacional, nunca as famílias brasileiras de camadas médias destinaram tão grande parte de seu orçamento à educação de seus filhos, nunca se teve disponíveis tantos resultados de pesquisa sobre a realidade brasileira (são centenas de dissertações e teses defendidas anualmente, só na área de Educação) e, sobretudo, sob os auspícios do Banco Mundial, nunca o país investiu tanto na formação continuada de professores (SILVA, 2005, p.382).

Para Libâneo (2007), o tema da formação de professores assume atualmente no Brasil uma importância crucial, devido ao impacto das atuais transformações econômicas, políticas, sociais e culturais na educação e no ensino, conduzindo a uma reavaliação do papel da escola e dos professores.

A escola com que sonhamos é aquela que assegura a todos a formação cultural e científica para a vida pessoal, profissional e cidadã, possibilitando uma relação autônoma, crítica e construtiva com a cultura em várias manifestações: a cultura provida pela ciência, pela técnica, pela estética, pela ética, bem como cultura paralela (meios de comunicação de massa) e pela cultura cotidiana (LIBÂNEO, 2007, p.7).

O desafio da educação escolar consiste, assim, em oferecer serviços de qualidade de modo que os alunos tenham acesso a melhores e mais efetivas condições de exercício da liberdade política e intelectual. Para tanto, é importante que a formação de professores garanta alguns aspectos essenciais para esse profissional, como destaca Libâneo (2007):

Novas exigências educacionais pedem às universidades e cursos de formação para o magistério um professor capaz de ajustar sua didática às novas realidades da sociedade, do conhecimento, do aluno, dos diversos universos culturais, dos meios de comunicação. O novo professor precisaria, no mínimo, de uma cultura geral mais ampliada, capacidade de aprender a aprender, competência para saber agir na sala de aula, habilidades comunicativas, domínio da linguagem informacional, saber usar meios de comunicação e articular as aulas com as mídias e multimídias (LIBÂNEO, 2007, p.10).

Sabemos que a formação de educadores está passando por um momento de revisão e crise em nosso país. Muitos são os motivos que provocaram esta situação. Entre eles podemos citar: o questionamento do papel exercido pela educação na sociedade e a falta de clareza sobre a função do educador no contexto atual.

Devemos ter claro que a educação é um fenômeno histórico-social que perdura toda a existência do ser humano, concretizando-se tanto nas relações das pessoas entre si quanto entre as pessoas e as demais manifestações do mundo natural, físico, social, tecnológico, espiritual, no decorrer dos tempos. A escola surge no contexto de acumulação de 
conhecimentos e experiências que se transmitem e se ampliam para garantir a existência, exigindo uma instituição como instância do saber e da formação humana (LIBÂNEO, 1995).

Percebemos que o contexto atual exige um novo perfil de educador, que vá além dos limites da profissionalização para o atendimento da sociedade capitalista, ou seja, das necessidades de mercado. Observamos constantes transformações na forma de compreender e atuar na realidade, cujo dinamismo e simultaneidade da realidade têm comprometido a construção de uma formação significativa dos profissionais.

Segundo Fidalgo (2009), todas essas mudanças exigem qualificação docente. Assim, a EAD surgiu como redentora de cursos instrumentais, estreitamente ligados às necessidades demandadas e capazes de garantir certa otimização dos espaços formativos.

Ainda segundo Fidalgo (2009), essa "cobrança" por formação, muitas vezes, esteve relacionada aos desígnios da lógica capitalista e pouca valorização foi destinada aos fundamentos constitutivos da qualificação dos docentes, que abrangesse o processo de socialização, fundado e orientado por princípios filosóficos comprometidos com a emancipação humana.

Para Moran (2000) existe uma expectativa de que novas tecnologias nos trarão respostas rápidas para o ensino, mas elas não são as soluções para todos os problemas educacionais. O que elas permitem é ampliarmos os conceitos de aula, de espaço e tempo, de comunicação audiovisual, e estabelecer novas pontes entre o presencial e o virtual, entre o estar juntos o estar conectados a distância:

Se ensinar dependesse só de tecnologias já teríamos achado as melhores soluções de muito tempo. Elas são importantes, mas não resolvem as questões de fundo. Ensinar e aprender são os desafios maiores que enfrentamos em todas as épocas e particularmente agora em que estamos pressionados pela transição do modelo de gestão industrial para o da informação e do conhecimento (MORAN, 2000, p.12).

Nessa linha, Masetto (2000) também enfatiza que não é a tecnologia que vai resolver ou solucionar o problema educacional no país, mas, se usada adequadamente, pode colaborar para o desenvolvimento educacional dos alunos e alunas.

Percebemos, na presente pesquisa, que questões referentes ao tempo e espaço são bastante mencionadas pelos sujeitos que participaram do Curso de Atendimento Educacional Especializado para Alunos Surdos, como uma das principais vantagens da EAD, como mostra as falas abaixo:

Como trabalho periodo integral e não tenho tempo para estudar no período noturno, acredito que será muito gratificante estudar à distância. Com isso ganho tempo e tranquilidade para estudar (Sujeito 2).

Penso que a educação a distância veio para nos auxiliar, é uma maneira de estarmos atualizadas e comprometidas com a educação, 
sem precisarmos nos ausentar tanto do contexto familiar, pois nos abre para a organização de horários (Sujeito 7).

Podemos utilizar várias ferramentas tecnológicas mais a que mais se utiliza é a Internet. A flexibilidade do tempo e horário de estudos é de grande importância nos dias de hoje, fazendo que mais pessoas possam ampliar seu conhecimento utilizando um periodo menor de tempo, pois podemos levar em conta o tempo gasto para conseguir chegar a um determinado local onde realizamos o curso (Sujeito 10).

Mill e Fidalgo (2006) enfatizam que as mediações tecnológicas na EAD dão a oportunidade para que tanto professores quanto alunos participem de atividades em tempos e espaços assimétricos e assíncronos. Assim, uma das principais características da EAD referese à flexibilidade dos tempos e espaços do trabalho.

Durante as discussões realizadas nos fóruns analisados, um dos sujeitos destaca que a EAD consiste em uma nova forma de ensinar e aprender, como podemos perceber em sua fala, descrita abaixo:

A concepção de Educação à Distância diz respeito a uma nova forma de ensinar e aprender, intermediada por tecnologias de informação e comunicação sem a necessidade de deslocamento. Tanto os papéis do professor quanto do aluno fogem ao ensino tradicional/presencial, o professor é um orientador/mediador enquanto o aluno é o agente do seu aprender (Sujeito 20).

Acreditamos que não é possível desvincular a discussão sobre concepções de EAD sem mencionarmos questões referentes ao ensino e a aprendizagem:

Tanto no ambiente de ensino/aprendizagem presencial quanto não presencial, temos de rever o uso que fazemos de diferentes tecnologias enquanto estratégias. Temos de ter clareza quanto ao paradigma educacional que estamos utilizando. Não basta trocar o uso do termo ensino por educação, se, na prática, não promovemos a inclusão do sujeito, pelo menos no que se refere aos processos de aprendizagem (CORRÊA, 2003, p.47).

Encontramos também Masetto (2000), definindo os conceitos de ensinar e aprender. Segundo ele, ensinar está ligado a um sujeito, que é o professor, que por suas diversas ações pode ser compreendido como alguém que transmite conhecimentos e experiências a um aluno que tem por obrigação receber, absorver e reproduzir informações recebidas. Já o conceito de aprender está diretamente relacionado ao aluno, que, por suas ações - que envolvem ele próprio, colegas e professores - pesquisa, dialoga, debate, desenvolve competências pessoais e profissionais, atitudes éticas, políticas, muda comportamentos, transfere aprendizagens, integra conceitos teóricos com realidades práticas, relaciona e contextualiza experiências e, 
entre outras coisas, resolve problemas.

Nessa perspectiva, alunos e alunas se desenvolvem e o professor é concebido como um mediador entre o aluno e a aprendizagem, sendo então, o facilitador e motivador da aprendizagem. Durante as discussões nos fóruns analisados, nos deparamos com várias menções sobre a importância do aluno no processo de construção de sua aprendizagem:

A qualidade do curso à distância, somente nós alunos é que fazemos ser bom ou ruim, vai depender de nós pesquisarmos, ler e debater, enfim interagir com nossa turma. O curso a distância traz em nossa vida a oportunidade de sermos o que queremos ser (Sujeito 23).

A EAD se caracteriza pela intensa interação dos alunos nas atividades online e presencial. A motivação do aluno é o grande segredo para o sucesso do ensino à distância e o professor exerce a função de mediador e orientador no curso. Uma autonomia muito grande é exigida em cursos ministrados a Distância, as questões propostas se articulam por meio dos diálogos estabelecidos (Sujeito 30).

Para Masetto (2000), não é fácil para o professor sair do papel de mero "transmissor" para mediador e orientador, como mencionado pelos sujeitos acima, afinal, sair dessa posição e entrar em diálogo direto com os alunos, correr o risco de ouvir perguntas que talvez não tenha as respostas e propor aos alunos momentos de busca por essas respostas, pode gerar desconforto e insegurança. Assim, confiar nos alunos, acreditar que são capazes e podem ser responsáveis pelos seus processos de aprendizagem junto com os professores, assumir que apesar da idade, podem retribuir atitudes de respeito, diálogo, responsabilidade; de assumir as consequências de seus atos, de profissionalismo.

A partir da percepção que todos têm com a EAD a oportunidade de aprender, alguns cursistas apresentaram representações que revelam questões referentes à inclusão social e democratização de conhecimentos, como podemos perceber abaixo:

Uma das principais características da EAD é a independência do espaço geográfico, permitindo que alunos oriundos de lugares variados tenham acesso ao ensino, sem a necessidade de deslocamento. Essa característica é primordial a um país com dimensões continentais como o nosso, principalmente, pela distribuição desigual da nossa população. Também, porque muitas das oportunidades se concentram nas regiões sul-sudeste, que dificultam o acesso por parte das outras regiões. (Sujeito 18)

Acredito que a EAD consiste na democratização do conhecimento, onde têm direito ao estudo, fazendo com que todos participem, tenham acesso às informações e troquem experiências (Sujeito 23).

Detectamos nessas falas que a EAD é compreendida como uma oportunidade de democratização do conhecimento. Bretãs (2004) enfatiza que os desiquilíbrios no acesso à 
informação e na produção do conhecimento são apontados como grandes fatores de exclusão social, e já se discute o peso do dinheiro na definição de uma agenda de pesquisas científicas:

\begin{abstract}
Assim, as drogas cosméticas passam a ser mais valorizadas que o estudo de vacinas contra a malária. $\mathrm{O}$ fechado controle das inovações pelas corporações multifuncionais acaba por ignorar as necessidades de milhares de pessoas. Os mercados competitivos podem ser considerados garantias para a eficiência, mas não para a equidade social (BRETÃS, 2004, p.100).
\end{abstract}

Assim, para Bretãs (2004) na face perversa da globalização, a internet é compreendida como um dos principais fatores da polarização entre ricos e pobres, o que favorece o acúmulo de informação destinada à elite econômica e contribui para dividir o mundo entre os que têm e os que não têm conhecimento.

Ainda segundo Bretãs (2004), o Human Development Report 1999 (HDRR99), elaborado pelo United Nations Development Programme - UNPD destacava que a globalização constitui-se como uma força dominante na última década do século $\mathrm{XX}$, organizando uma nova era de interação entre as nações, economias e pessoas. Alguns alunos do Curso de Atendimento Educacional Especializado para Alunos Surdos também enfatizam a questão da interação na EAD:

$\mathrm{Na}$ educação a distância os alunos estão todos interligados, porém não juntos fisicamente, se bem elaborado podemos aprender muito, pois nos oferece leituras nas quais somamos ao nosso conhecimento e trocamos experiência com outros participantes que vivem em locais que se não fosse por meio desse ambiente seria muito mais dificil a troca de experiências (Sujeito 2).

Assim como a maioria compartilho da crença de que a EAD tem sido uma forma de estudo indispensável e necessária, pois ela possibilita uma maravilhosa oportunidade de aprender e de realizar trocas significativas com várias pessoas. Ela tem o poder de atingir mais e mais pessoas nesta sua formatação "a distância”, principalmente para quem não pode ou não tem a condição de frequentar cursos presencias (Sujeito 6).

Mas o mesmo relatório HDRR99 aponta para os efeitos negativos da internet, enquanto acesso a conhecimentos, ligados ao crescimento de aspectos marginalizantes, como o aumento da insegurança e das desigualdades, classificando como "grotescas" as diferenças de qualidade de vida entre os países (BRETÃS, 2004), mas durante o ano de 2000 encontramos algumas intenções de possíveis políticas públicas em busca da inclusão social e formação para a cidadania: 
As tecnologias de informação e comunicação devem ser utilizadas também para a democratização dos processos sociais, para fomentar a transparência de políticas e ações de governo e para incentivar a mobilização dos cidadãos e sua participação ativa nas instâncias cabíveis (SOCIEDADE, 2000, p.45).

Em linhas gerais, percebemos que todas as falas dos cursistas, alunos e alunas do Curso de Atendimento Educacional Especializado para Alunos Surdos, apontam para representações positivas acerca da EAD. Os sujeitos apontam questões referentes a tempo, espaço geográfico, oportunidade de formação inicial e continuada e democratização do conhecimento como principais características dessa modalidade de ensino.

Em minha opinião essa modalidade de ensino auxilia na democratização do acesso e construção do saber/conhecimento, uma vez que muitos cursos são razoavelmente mais baratos que os presenciais e, sobretudo, permite ao aluno conciliar trabalho, estudo e família (Sujeito 17).

Nos dias de hoje o ensino a distância é uma ótima opção para quem não quer ir todos os dias a uma instituição de ensino, mas vale lembrar que precisa de maior tempo de dedicação (Sujeito 24)

Os cursistas também mencionaram nos fóruns algumas de suas experiências em EAD:

Na Educação a distância faço minha segunda graduação a distância (semipresencial) e minha pós-graduação a distância; terei que me deslocar apenas para a defesa da minha monografia. Se não fosse a distância, posso afirmar com certeza que seria impossível para mim conciliar os estudos com o trabalho, marido, filhos, ... Eu sempre recomendo e incentivo quem me pergunta sobre a EAD (Sujeito 7)

Creio na EAD; já faço curso a distância há alguns anos principalmente na área de Educação Especial Inclusiva e acredite adquiri bastante conhecimento inclusive na área da informática onde preciso a todo o momento pelo fato de trabalhar na Sala de Recursos com alunos com necessidades educativas especiais (Sujeito 31).

Sentimos falta de posicionamentos críticos acerca da EAD nas representações dos cursistas, mas detectamos que durante os fóruns analisados a interação entre professores, tutores e alunos foram uma constante. A troca de ideias e socialização dos relatos e das reflexões feitos pelos cursistas demonstraram que a EAD pode constituir-se uma das oportunidades de interação com diferentes interlocutores, permitindo a interação de distintos olhares sobre os temas estudados. 


\section{Considerações Finais}

Sabemos que são muitas as definições sobre EAD. Há autores que se baseiam na ideia de autoaprendizagem ou de autonomia possíveis na EAD. Para Belloni (1999, p.6), a EAD é centrada no "sujeito aprendente, considerando como um indivíduo autônomo, capaz de gerir seu próprio processo de aprendizagem". Pensa-se nessa autonomia já que professores e alunos estão distantes espacialmente. Há, então, por parte do aluno a necessidade de iniciativa, autodisciplina e a autonomia em organizar seus próprios horários e tempos de estudos. Logo, o aluno é desafiado a pesquisar e entender o conteúdo de forma a interagir com a disciplina.

Para outros, a Educação a Distância pode ser compreendida como um distanciamento entre alunos e professores, uma separação espacial (geográfica/local) (Gouvêa e Oliveira, 2006; Tori, 2010). Alunos e professores em locais diferentes e em momentos diferentes ou alunos juntos, mas em lugar diferente do professor. Existe um distanciamento espacial; entretanto, estão próximos considerando as potencialidades da tecnologia. Conforme Valente e Mattar (2007, p.19), o distanciamento físico entre os participantes "não implica em distanciamento humano", já que a aprendizagem será mediada pelas tecnologias interativas que propõem debates, pesquisas e discussão através de fóruns, mensagens e chats.

Para Moran (2000), essas tecnologias interativas vêm mostrando que a interação e interlocução entre professores e alunos na EAD acontecem de forma eficaz, o que deveria ser a base de qualquer processo ensino-aprendizagem. Para o autor, os avanços tecnológicos vêm proporcionando uma maior interatividade entre as pessoas e vencendo a distância física entre educador e educando.

Em linhas gerais, acreditamos que no contexto de mudanças no âmbito econômico e educacional, a EAD se revelou uma forma de tornar a educação mais democrática, levando mais facilmente, aos mais diferentes espaços geográficos, acesso à informação e aquisição ao conhecimento.

Entendida como uma modalidade de educação, a EAD é uma oportunidade de preencher os espaços vagos do processo ensino aprendizagem que as atividades presenciais não alcançaram. Nesse sentido, é importante ressaltar que a EAD não deve ser considerada uma substituta da educação convencional. As duas, tanto a presencial quanto a distância, fazem parte do mesmo processo.

Percebemos que questões sobre autonomia, democratização e espaço geográfico, são apontadas como as principais características da EAD nas representações dos sujeitos pesquisados.

Através das reflexões e diálogos tecidos sobre a EAD nesse trabalho, percebemos que houve interação entre professor e aluno no curso. E mais, a EAD conseguiu mostrar suas possibilidades, características e potencialidades.

Enfim, por estabelecer uma comunicação de múltiplas vias, a EAD superou, para esses sujeitos, os limites de tempo e espaço com a sua evolução e tem feito cada vez mais professores se envolverem em cursos a distância. Nota-se que a EAD, no que se refere ao acesso às mais diversas informações que possibilitam o desenvolvimento da formação 
profissional e pessoal dos sujeitos, tornou-se uma facilitadora, proporcionando uma maior interatividade entre as pessoas e vencendo a distância física entre educador e educando, corroborando assim com a democratização do saber.

\section{Referências}

BELLONI, M. L. Educação a distância. Campinas, SP: Autores Associados, 1999.

BRASIL, Programa de Formação Continuada de Professores na Educação Especial. Ministério da Educação/Secretaria de Educação Especial-MEC/SEESP: Brasília, Edital $n^{\circ} 02$, 2007.

BRETÃS, Beatriz. Comunicação mediática no processo ensino/aprendizagem. In: COSTA, J.W.da; OLIVEIRA, M.A.M. (orgs.). Novas linguagens e novas tecnologias: educação e sociabilidade. Petrópolis, RJ: Vozes, 2004.p.81-110.

CORRÊA, Juliane. Novas tecnologias da informação e da comunicação; novas estratégias de ensino/aprendizagem. In: COSCARELLI, Carla Viana. Novas Tecnologias, novos textos, novas formas de pensar. Belo Horizonte: Autêntica, 2003. p.43-50.

FIDALGO, F.; OLIVEIRA, M.A.M.; FIDALGO, N.L.R. Trabalho docente, formação continuada e tecnologias. In: FIDALGO, F.; OLIVEIRA, M.A.M.; FIDALGO, N.L.R.(orgs.). A intensificação do trabalho docente: tecnologias e produtividade. Campinas, SP: Papirus, 2009. p.135-161.

GOUVÊA, G. e OLIVEIRA, C. I. Educação a Distância na Formação de Professores: Viabilidades, potencialidades e limites. Rio de Janeiro: Vieira \& Lent, 2006.

JODELET, Denise. Representações Sociais: um domínio em expansão. In: JODELET, Denise (org.). As Representações Sociais. Rio de Janeiro: EdUERJ. 2001. p.17-44.

LIBÂNEO, José Carlos. Tendências Pedagógicas na Prática Escolar. In: LIBÂNEO, José Carlos. Democratização da Escola pública - a pedagogia crítico-social dos conteúdos. São Paulo: Loyola, p.19-44, 1995.

MASETTO, Marcos T. Mediação pedagógica e o uso da tecnologia. In: MORAN, José Manuel; MASETTO, Marcos T.; BEHRENS (Org.) Novas Tecnologias e mediação pedagógica. Campinas:SP: Papirus, 2000. p.133-173.

MILL, D. e FIDALGO, F. Educação a distância e trabalho docente virtual: Sobre tecnologia, espaços, tempos, gênero e coletividade na Idade Mídia. Trabalho \& Educação, vol.15, p.119120.

MOSCOVICI, Serge. Das representações coletivas às Representações Sociais: 
elementos para uma história. In: JODELET, Denise (org.). As Representações Sociais. Rio de Janeiro: EdUERJ. 2001. p.45-66.

Representações Sociais: investigações em Psicologia Social. Traduzido por Pedrinho A. Guareschi. Petrópolis, RJ: Vozes, 2003.

MORAN, José Manuel. Ensino e aprendizagem inovadores com tecnologias audiovisuais e telemáticas. In: MORAN, José Manuel; MASETTO, Marcos T.; BEHRENS (orgs.) Novas Tecnologias e mediação pedagógica. Campinas:SP: Papirus, 2000. p.11.65.

. $O$ que é educação a distância. Disponível em http://www.eca.usp.br/prof/moran/dist.htm. Acesso: 20 Jan. 2012.

TAKAHASHI, Tadão. (Org.). Sociedade da informação no Brasil: livro verde. Ministério da Ciência e Tecnologia, 2000.

TORI, R. Educação sem distância: as tecnologias interativas na redução de distâncias em ensino e aprendizagem. São Paulo: Editora Senac São Paulo, 2010.

VALENTE, C. e MATTAR, J. Second Life e Web 2.0 na Educação: o potencial revolucionário das novas tecnologias. São Paulo: Novatec, 2007.

RECEBIDO EM: 08/03/2016

APROVADO PARA PUBLICAÇÃO EM: 29/06/2016 